\title{
Understanding University Students' Identity Through Engagement in Informal Physics Programs
}

Caleb Rispler, Brean Prefontaine, and Kathleen Hinko

Department of Physics and Astronomy, Michigan State University, 220 Trowbridge Rd, East Lansing, MI, 48824

A physics student's identity is predicated on a multitude of factors, such as research, classes, and activities outside the classroom. Many students choose to participate in informal physics teaching programs during college; however, these programs are an understudied portion of a physics student's experience. We hypothesize that university students' science identity is reshaped by interactions and experiences they have in these programs. We focus on a student group that does demonstrations at local K-12 schools and organizations. Preand post- interviews were collected with undergraduate participants in this group who went on an intensive week-long trip to rural areas in the state. Here, we extend our previous work using a Communities of Practice framework to analyze these interviews. We operationalize students' movement toward or away from central membership as well as look at the intersection of other physics, academic, and personal communities with the informal physics program community.

2019 PERC Proceedings edited by Cao, Wolf, and Bennett; Peer-reviewed, doi.org/10.1119/perc.2019.pr.Rispler Published by the American Association of Physics Teachers under a Creative Commons Attribution 4.0 license. Further distribution must maintain attribution to the article's authors, cover page, and DOI. 


\section{INTRODUCTION}

Physics education researchers are looking to understand the factors that play a role in shaping the identities of physics students. In the past decade, substantial work has been done towards discerning the role informal experiences play in shaping a physics student's identity [1]. Past research has focused on how undergraduate and graduate students choose to freely take part in physics related experiences beyond their coursework and research. These experiences are different from the formal experiences within a classroom due to the degree of agency experienced through voluntary participation. Thus, these experiences are potentially powerful for identity development [1]. In this work, we take identity to be defined as being a member of a CoP and having a sense of belonging.

Informal learning at the college level is often found in opportunities that are funded and offered through the physics departments, which allows students to interact with physics content and practices through public outreach. One such example of this is the American Physical Society's officially sanctioned student organizations, Society of Physics Students and Sigma Pi Sigma, which list "outreach services to the campus and local communities" in their mission statement [2].

In prior work, we postulated that certain informal physics groups can function as Communities of Practice, especially if the informal activities are designed to be intensive, immersive, or meaningful. We have operationalized the Communities of Practice theory in the context of two different kinds of informal physics education programs: a demonstration program called Science Theatre at Michigan State University and a K-12 afterschool physics program called PISEC at the JILA Physics Frontier Center at the University of Colorado Boulder [3]. These studies showed that the Communities of Practice theory can apply to informal physics programs and that participation within these programs can have a positive impact on students' attitudes towards outreach [4].

In this paper, we build on these previous results and present a fine-grained look at how university students who engage in an informal physics program can build competence as an informal physics educator and as a member of a disciplinary scientific community. Through previous utilization of the theoretical model on an informal physics program, we demonstrated that the program at Michigan State can be modeled by the Communities of Practice framework. Here, we consider a group of five undergraduate members of Science Theatre that participated within this informal physics/science program through Michigan State University. In this paper, we aim to further understand the impact of informal experiences on students by investigating their negotiation of and movement as a member in correlation to their participation which prompted our research question: What aspects of Science Theatre membership support participants becoming a more central member within the community? By taking a close look at community membership, we can start to understand how membership within informal physics programs can support physics identity development.

\section{COMMUNITIES OF PRACTICE FRAMEWORK}

The Community of Practice (CoP) framework was developed in 1991 by Lave and Wenger to identify "groups of people who share a concern or a passion for something they do and learn how to do it better as they interact regularly" [5]. In physics education research, the framework has recently been used to look at the Learning Assistant experience and students taking advanced lab courses. In order to be considered a CoP, a group must have three attributes: have some shared goal or expertise (domain), help each other achieve goals (community), and have a set of norms, repertoire and shared information to achieve the domain (practices).

Competence is the main factor that affects an individual's membership within the community of practice. In this example, competence is defined by the community and what it values through engagement and participation. There are three dimensions of the competence for a community of practice: accountability to the enterprise, mutuality of engagement, and negotiability of the repertoire. These dimensions of competence lay the framework for which the dimensions of identity can be understood to help determine the degree of membership an individual holds within the CoP. That means that a competent member can be defined as a central member that is able to achieve all three of these dimensions. Apart from the dimensions of competence, Wegner also identified different categories that link the communities of practice to identity such as negotiated experiences, learning trajectories, and nexus of multi-membership. These categories determine what experiences within the community of practice help one become a more competent, central member of that community. In this work, we focus on the competence and membership levels of individuals within the community of practice; this approach allows us to probe the nature of the CoP itself, as well as individuals' identities.

The accountability to the enterprise construct is concerned with the idea that a CoP must be defined by a shared domain or goal of interest in which every member pursues. Accountability analyzes how members understand the goals/objectives of the community, how members take responsibility and embrace those goals, and their constant negotiation and redefinition of them. Through the coding, this construct captures how interviewees interact with and view the goals of the community.

The mutuality of engagement construct is associated with the idea that a CoP must have a community or sense of members exchanging ideas and information. This dimension details how members engage with other members to establish relationships within the community and is the basis for formation of an identity through participation. Through the coding, this construct captures how interviewees interact with other members within the community.

The negotiability of the repertoire construct is affiliated with the practice aspect of the CoP and how members work together to achieve the group's goals. In relation to the Science Theatre program, it is the history and experiences cre- 
ated through negotiation and engagement with other members of the community. This concept translates to a personal set of events, references, memories, and experiences that create relations of negotiability with respect to the repertoire of practice. Through the coding, this construct captures how interviewees reflect on their acquired ability to use skills, language, and resources of the practice.

\section{SCIENCE THEATRE CONTEXT}

Science Theatre is an outreach program through Michigan State University that consists of undergraduate and graduate students that perform science demonstrations and stage shows. We investigate membership ideas and the relevance of the communities of practice framework within this group. Funding for Science Theatre comes from the physics department and their aim is to "get children and adults alike excited about the wonders of science"[9]. In order to carry out this goal, the group has developed a variety of physics and other science demonstrations that are used either on stage (generally for an audience of local K-12 students) and hands-on environments (i.e. at the MSU science festival or at local K12 schools). Most of the outreach events are one-time and between around 1-2 hours in length. Students in the group can choose to participate in as many of the one-time events as may fit in their schedule. The group is comprised of 40 student volunteers from a variety of STEM majors, some of whom have officer roles, a staff coordinator, and a physics faculty advisor. The group organizes itself in a large multiroom workspace found in the basement of the MSU planetarium to store equipment, create and test new demos, and to socialize.

One unique aspect of Science Theatre is the opportunity for members to participate in an intensive outreach experience during a spring break trip through rural areas of the state. For this week-long trip, members of MSU's Science Theatre can choose to volunteer to drive demonstration equipment to northern rural Michigan. While there, they put on a multitude of stage shows at K-12 schools who have limited connection with universities. They spend that week, Monday through Friday, traveling from school to school in 3-4 person teams to complete presentations during the students' school days. Once the shows are done for the day, the teams reconvene to eat dinner, debrief on the day, and can choose to interact further to pass time. Nine students (eight undergraduates and one graduate) volunteered for the 2018 spring break trip in which students performed these stage show at more than 60 schools.

Previous research has shown that Science Theatre can be treated as a Community of Practice where the three main aspects of the group consisting of: the students share the domain of getting the general public excited about science, a community of undergraduate and graduate students who are able to hold one of the twelve officer positions, and a practice that consists of a wide range of demonstrations and scripted shows [6]. Furthermore, we hypothesize that participation in the spring break trip can be a highly impactful activity for Science Theatre members. Expanding on our recent work, we aim to analyze how competence within the group can be affected by sub-communities and overall involvement within the program.

\section{METHODOLOGY}

By treating Science Theatre is a CoP, we seek to determine the competence of the student participants and how levels of competence can be affected by the communities in which the participants are a part of. To accomplish this goal, we designed a qualitative study in which participants were asked about their experiences within Science Theater and the spring break trip. During the spring of 2018, 10 matched interviews (5 pre-trip and 5 post-trip) were collected from undergraduate students who had participated in the Science Theatre Spring Break trip. All of the students were interviewed during the two weeks leading up to spring break and again during the two weeks following the trip. The semi-structured interviews followed a pre-trip protocol that focused on competence related to their involvement with Science Theatre, future career plans, and expectations of the trip. The post-trip protocol focused on feelings about the trip, specific demos performed, and the impact of going on the trip.

To test the efficacy of the CoP framework through the competence constructs, we have chosen to look at all of the interviews from the data set and analyze them in multiple ways. To build upon last year's case study, we determined that on top of the competence codes associate with Science Theatre, codes that identified other specific communities, groups or interests of the subjects would be added to the data in order to illuminate how multimembership in communities can affect participants.

Two researchers analyzed the interviews by coding with the three competence constructs. Complete ideas (often a whole sentence or a significant portion of the sentence) were coded with the competence codes. We also did not code the same idea twice (ie when interviewees repeated the idea to clarify a statement, this was only counted once). Once the findings had been coded, we added classifications (in the form of subcodes) to the competence construct in order to designate the relationship of the code to more central or peripheral membership in Science Theatre ("insider", "outsider", "neutral"). A comparison between all codes was conducted among the two researchers and any discrepancies within the pre- and post- interviews were discussed and resolved. This process also helped redefine the operationalized codes and was used to further validate the process.

When applying a quantitative analysis, we found it useful to use the percentage (out of 100) in which codes appeared while constructing graphical representations in order to help negate bias that could stem from uneven interview lengths and variation of responses. Another analytical technique that 
we utilized was to combine the pre- and post- interviews into a single data source in order to minimize biases involved with different questions that were asked within the pre- and the post- trip interviews. Thus, there was a total of 5 participants, with a total of 10 interviews that were analyzed.

\section{ANALYSIS}

For our analysis, we find that all three of the competence constructs were present for all five of the participants, with the pre- and post- interviews combined. Table I summarizes the data set of all five students: their pseudonym, grade level, major, role in Science Theatre, years in Science Theatre, and number of times they have been on the trip. Figure 1 represents each of the five interviewees by breaking down the percentages of the competence codes that are found within each interview. By recognizing that all three competence constructs are experienced and discussed by all of the interviewees, we affirm that Science Theatre is an informal group that can be modeled by the Communities of Practice framework.

\begin{tabular}{|c|c|c|c|c|c|}
\hline Pseudonym & Grade level & Major & Role in ST & $\begin{array}{c}\text { \# of years in } \\
\text { ST }\end{array}$ & $\begin{array}{c}\text { \# of times } \\
\text { on the trip }\end{array}$ \\
\hline Dylan & Sophomore & Physical science & Officer & $\sim 2$ & Second time \\
\hline Patrick & Senior & Engineering & Officer & $\sim 4$ & First time \\
\hline Matt & Freshman & Psychology & Member & $<1$ year & First time \\
\hline Grace & Freshman & Physics & Member & $<1$ year & First Time \\
\hline Tom & Freshman & Physics & Member & $<1$ year & First Time \\
\hline
\end{tabular}

TABLE I. An overview of all interviewees' grade level, major, role, number of years in Science Theatre, and number of times participating in the trip

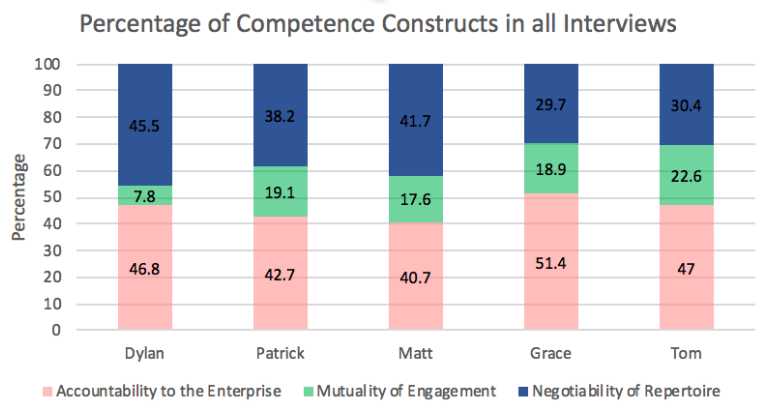

FIG. 1. An overview of the frequency of competence codes

While statistical analysis has not been carried out on the quantitative data, we feel as though it is still important due to the fact that it can lead us to a more robust analysis of the qualitative data. One area of interest when we drew comparisons between Table I and Figure 1 is that Dylan has two years of experience on the spring break trip and this seems to correlate with Dylan expressing more Negotiability of Repertoire. After the Dylan's previous year of experience on the trip, it appears that he has developed a greater repertoire on which he can understand the demos and the physics behind them. When evaluating Dylan's interview, he has an in-depth explanation of his experience and his enjoyment of some of the demos:

I'm an officer [...] I know what I'm doing and I like it. I feel comfortable with a lot more stuff. I've done a lot more shows this year.

Dylan then goes on to say that he has developed different strategies for different audiences by adding in his own previous knowledge:

And there is one audience that actually had highschoolers in it. [...] And I took out a whiteboard and was like, 'Okay, high-schoolers. Let's talk about activation energy.' So then I blew their minds or bored them with that. I don't know what their reaction was to that, whether they liked it or not. But I showed the high-schoolers the energy part of why catalysts work.

This knowledge of how to present the demos and science background to the students in an understandable way was obtained from Dylan's previous experience on the trip and within the organization of Science Theatre. From this, it appears that as a student obtains more experience on the spring break trip and within the community, that they also gain a larger repertoire of experiences to pull from.

Furthermore, in all of the interviews, it appears that the students have a similar amount of Accountability to the Enterprise. This may play a role into why a student may choose to participate in such an immersive outreach experience, such as the spring break trip. An example of this can be seen when Grace discusses her perceived impact of the trip:

I think the impact of the trip on me was kind of just showing me it's important to reach out and share things with others because most people don't spend their spring break giving back. I think it just seems like the trip gave me an opportunity to be like, '[...] it's important to share what you do with others even if you're not directly telling them about the science you do at home or at your lab you're telling them about science in general so that's doing almost the same thing so.'

This quote illustrates how Grace is reflecting on the importance of the goal of outreach, and moreover the specific goals of Science Theatre. Her accountability after the spring break trip seems to be affirmed in her consideration of the experiences that took place during the trip and how she believes that outreach, such as Science Theatre, is important within the broader community. We saw that most of the students shared about these meaningful experiences and about 
how the trip has impacted them and ultimately increased their accountability towards the program.

Often, interactions with other members can further accountability to Science Theatre; positive interactions amongst members of the group can additionally allow students to flourish within the community. Within the CoP framework, we characterise interactions between members as Mutuality of Engagement. The overview of the competence codes within Tom's interview, seen in Figure 1, indicate a larger amount of Mutuality of Engagement as compared to other interviewees. These interactions between members can be seen having a great effect on his future as a member of Science Theatre. Tom discusses being friends with other officers within Science Theatre and how this has impacted his decision to run for an officer position during the following year when he says "Because now I know a lot of people on E-Board, and during the trip, they convinced me that they thought I should be on it." Furthermore, Tom also discusses how interacting with other members of the group helped him learn more about the demos while on the trip:

[...] if you have a certain number of demos in your car, you're going to do the same ones multiple times in the day. And so if you're not confident on one, but you're super confident in another one, and somebody else isn't confident on that one, you guys in the first show can do the ones that you're confident on. And then you watch the other person. [...] And now you've both seen somebody good at them do it.

The interactions that members such as Tom have within the group, especially those among members with positions of power, seem highly influential in creating members that are more accountable. This cycle helps allow general members become more inward members that ultimately become larger parts of Science Theatre. Through these examples it appears that by utilizing the Communities of Practice framework, Science Theatre can be shown to be exceptionally impactful on the identities of the students within the group.

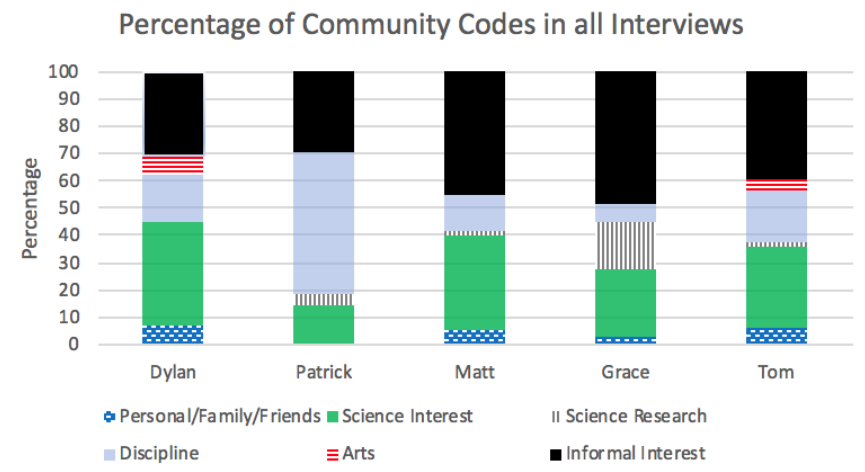

FIG. 2. An overview of frequency of "community codes" excluding the Science Theatre community.

Figure 2 shows the percentage breakdown of each "community code" and their prevalence amongst all 5 interviews excluding everything that was coded as the Science Theatre community code. Our was the fact that the Science Theatre community code comprised a significant chunk of the communities coded and therefore skewed the resulting graphs. By looking at the remaining codes within the interviews, we are better able to understand what other communities the interviewees are actively involved in and that these communities may interact and overlap with the Science Theatre community. It is important to note that informal interest, discipline (college major or career interest), and general science interest were found among all interviews and should be noted as playing a role in the development of a physics identity.

From this data, it is evident that science interest, informal interest, and discipline, all intersect with the participants' identity as member of the Science Theatre Community of Practice. We plan to investigate further the relevance of other communities and interests, and how they might give more insight into how a member may enter an informal physics program and move within the group. By breaking down the competence codes further, we aim to see if certain communities could impact changing membership levels over time.

\section{CONCLUSIONS}

In this work, we have expanded the Communities of Practice framework from a previous case study and showed its viability over a data set of five interviewees. Through this work, the informal physics program, known as Science Theatre, can be successfully shown to possess all three essential characteristics of a CoP. Additionally, preliminary analysis suggests that there are possible correlations between cumulative repertoire and years in which the student has participated in the spring break trip. Due to the layers of our coding scheme, future work can include looking at the communities in comparison to the competence codes and how certain other identities, such as discipline, science interest, and informal interest, may give insight into what drives a student to complete this meaningful outreach program. Further quantitative analysis will be conducted in order to detect possible correlations within the communities, competence, and the development of identity within the group.

This and future work provide the important groundwork for understanding what leads a student to engage with informal programs and how these programs affect participant's physics identity. Understanding the nature of participation within informal physics programs allows us to explore how environments can affect the development of a physics identity.

\section{ACKNOWLEDGMENTS}

This work was supported by NSF \#1423496 and the Lyman Briggs Undergraduate Research Award. 
[1] National Research Council. Learning Science in Informal Environments: People, Places, and Pursuits. 2009.

[2] https://www.spsnational.org/about. Retrieved July 5, 2018.

[3] Prefontaine, B., et. al. "Intense Outreach: Experiences shifting university students' identities." PERC Proceedings, Washington, D.C. July 2018.
[4] Fracchiolla, C., et. al. "Is participation in public engagement an integral part of shaping physics students' identity?" 2019 GIREP International Conference Proceedings San Sebastian, Spain. July, 2018.

[5] Lave, J. and E. Wenger. Situated Learning: Legitimate Peripheral Participation. 1991.

[6] https://web.pa.msu.edu/sci_theatre/. Retrieved April 12, 2018. 